\title{
Further Observations on the Teratogenic Action of the Thyroid Stimulating Hormone'
}

\author{
ALLAN R. BEAUDOIN \\ Department of Anatomy, The University of Michigan, \\ Ann Arbor, Michigan
}

\begin{abstract}
Pregnant Wistar Albino rats were injected intraperitoneally with the thyroid stimulating hormone (TSH), obtained from several different suppliers, and with the dye trypan blue. Twenty USP units of TSH were injected on days 7 to 10 of pregnancy, one quarter of the total dose each day. Trypan blue was injected as a single subteratogenic dose ( $0.6 \mathrm{mg} / 100 \mathrm{gm}$ maternal body weight) on day 8 . Autopsy was on day 20 . Some TSH prepared as a pituitary extract possessed very weak teratogenic activity, possibly limited to the production of hydronephrosis and hydroureter. Other TSH samples similarly prepared had no embryotoxic or teratogenic effect. Thyrotropin prepared from bovine serum exhibited distinct teratogenic activity causing the production of various malformations in the offspring of treated mothers. A subteratogenic dose of trypan blue enhanced the teratogenic activity of the serum prepared TSH sample but had no effect on TSH prepared from pituitary glands. The results of this experiment suggest that there is something in the nature of preparation of TSH from bovine serum that causes it to possess teratogenic activity.
\end{abstract}

The thyroid stimulating hormone (TSH) was first reported to possess teratogenic activity in rats by Beaudoin and Roberts ('66). A re-evaluation of the original report is necessary in light of the results to be presented in this paper. This study was undertaken to test the teratogenic activity of samples of TSH obtained from several different suppliers. Each TSH sample was also tested for possible interaction with the disazo dye trypan blue.

\section{MATERIALS AND METHODS}

Virgin female Wistar Albino rats (Albino Farms, Red Bank, New Jersey) were used. The animals were maintained on a Rockland Complete Rat Diet ad libitum, with supplemental feedings of lettuce. Day 0 of pregnancy was considered to begin on the morning sperm were found in the vaginal smear. Two experimental groups of rats were used in this study; the first group received thyrotropin alone and the second group received trypan blue in addition to thyrotropin. The thyroid stimulating hormone was prepared in sterile saline and 20 USP units were administered intraperitoneally in one-quarter doses at 24-hour intervals on days $7,8,9$, and 10 of gestation. Trypan blue was prepared as a $0.12 \%$ solution and injected intraperitoneally on day 8 of pregnancy, in a subteratogenic dose of $0.6 \mathrm{mg}$ per $100 \mathrm{gm}$ maternal body weight. Pregnancy was terminated on day 20 , uterine resorption sites were counted, and the fetuses were recovered, weighed, and fixed in Bouin's fluid or $95 \%$ alcohol for subsequent examination for malformations. The fetuses fixed in 95\% alcohol were prepared for staining with alizarin red for visualization of the skeleton. Fetuses fixed in Bouin's fluid were free-hand sectioned with a razor blade into $2 \mathrm{~mm}$ slices and each slice examined for malformations.

The thyrotropin used in this study was obtained from The Endocrinology Study Section of The National Institutes of Health (NIH); Sigma Chemical Co., St. Louis, Missouri; Armour Pharmaceutical Company, Chicago, Illinois; and Nutritional Biochemicals Corp. (NBC), Cleveland, Ohio. All thyrotropin samples were prepared from pituitary glands except one from NBC that was prepared from bovine serum.

\section{RESULTS}

Table 1 summarizes the results of treatment of pregnant rats with thyrotropin from NBC, NIH, Armour, and Sigma. The

\footnotetext{
1 Supported by Public Health Service Research grant HD-00400 from the National Institute of Child Health and Human Development.
} 
TABLE 1

Effect of intraperitoneal injection of 20 units thyrotropin into pregnant Wistar albino rats ${ }^{1}$

\begin{tabular}{|c|c|c|c|c|}
\hline $\begin{array}{l}\text { Source of } \\
\text { hormone }\end{array}$ & $\begin{array}{l}\text { No. } \\
\text { implantation } \\
\text { sites }\end{array}$ & $\begin{array}{l}\text { No. and \% } \\
\text { resorbed } \\
\text { or dead }\end{array}$ & $\begin{array}{l}\text { No. and } \% \\
\text { survivors } \\
\text { malformed }\end{array}$ & $\begin{array}{l}\text { \% implanta- } \\
\text { tion sites } \\
\text { affected by } \\
\text { treatment }\end{array}$ \\
\hline \multicolumn{5}{|l|}{$\mathrm{NBC}^{2}$} \\
\hline 6193 & 224 & $74(33.0)$ & $37(24.6)$ & 49.6 \\
\hline 9753 & 203 & $49(24.2)$ & $26(16.2)$ & 37.0 \\
\hline $\mathrm{NIH}^{3}$ & 59 & 0 & 0 & 0 \\
\hline \multicolumn{5}{|l|}{ Armour ${ }^{4}$} \\
\hline fall 1966 & 48 & $6(12.5)$ & 0 & 12.5 \\
\hline spring 1967 & 63 & $3(4.8)$ & $5(8.3)$ & 12.7 \\
\hline \multicolumn{5}{|l|}{ Sigmas } \\
\hline $85 B 2540$ & 33 & $8(24.2)$ & $1(4.0)$ & 27.3 \\
\hline $96 \mathrm{~B} 1760$ & 95 & $3(3.2)$ & $6(6.5)$ & 9.5 \\
\hline
\end{tabular}

1 One-quarter dose injected on days $7,8,9$, and 10 .

2 Nutritional Biochemicals Corp., Cleveland, Ohio. Prepared from bovine serum.

3 A gift from Endocrinology Study Section. Prepared from pituitary glands.

4 Armour Pharmaceutical Company, Chicago, Illinois. Prepared from pituitary glands.

5 Sigma Chemical Co., St. Louis, Missouri. Prepared from pituitary glands.

TABLE 2

Comparison of the teratogenic activity of 20 units thyrotropin from different sources

\begin{tabular}{lcccc}
\hline $\begin{array}{c}\text { Source of } \\
\text { hormone }\end{array}$ & $\begin{array}{c}\text { No. } \\
\text { implantation } \\
\text { sites }\end{array}$ & $\begin{array}{c}\text { No. and } \% \\
\text { resorbed } \\
\text { or dead }\end{array}$ & $\begin{array}{c}\text { No. and } \% \\
\text { survivors } \\
\text { malformed }\end{array}$ & $\begin{array}{c}\% \text { implanta- } \\
\text { tion sites } \\
\text { affected by } \\
\text { treatment }\end{array}$ \\
\hline NIH ${ }^{1}$ & 59 & 0 & 0 & 0 \\
Armour $^{1}$ & 111 & $9(8.1)$ & $5(4.9)$ & 12.6 \\
Sigma $^{1}$ & 128 & $11(8.6)$ & $7(5.9)$ & 14.1 \\
NBC-p $^{1}$ & 65 & $5(7.7)$ & 0 & 7.7 \\
NBC-s $^{2}$ & 427 & $123(28.8)$ & $63(20.7)$ & 43.6 \\
\hline
\end{tabular}

1 Pituitary extract.

2 Prepared from bovine serum.

sample from NIH was innocuous to rat development. The results obtained with NBC sample \#6193 have been published (Beaudoin and Roberts, '61). Sample \#9753 was used in identical fashion one year later. The differences observed in the results are not statistically significant. Thyrotropin obtained from Armour was of the same lot, although used at two different times during the year. A comparison of fall-treated animals with spring-treated animals revealed differences in the numbers resorbed and malformed, but the overall effect on implantation sites was the same. Fall treatment caused only resorptions, whereas spring treatment caused resorptions and malformations. Two different samples were obtained from Sigma. Sample 85B2540 was much more active in causing resorptions than sample 96B1760. Few malformations were caused by either sample.
Table 2 compares the teratogenic activity of TSH from all sources. The results from each source have been combined for purposes of comparison. As can be seen from the table, only the NBC thyrotropin prepared from bovine serum had marked teratogenic activity. Note especially that the NBC sample prepared from pituitary glands lacked teratogenic activity.

The types of malformations observed following TSH treatment are listed in table 3 and illustrated in figures 1-8. Except for one case of hydrocephalus the Sigma and Armour samples produced only hydronephrosis and hydroureter. A variety of defects were produced by the serum-prepared thyrotropin from NBC.

The results of combined treatment of pregnant rats with TSH and a subteratogenic dose of trypan blue are shown in table 4 . The pituitary-prepared thyrotropin 
exhibited no significant interaction with trypan blue. The serum-prepared thyrotropin, on the other hand, exhibited a marked interaction with the dye. The combined treatment doubled the incidence of malformations ( $P=0.001)$ but had no effect on the incidence of resorptions $(P=0.5)$.

\section{DISCUSSION}

The results of this experiment confirm our earlier observations on the teratogenicity of the thyroid-stimulating hormone derived from bovine serum. It was discovered in this experiment that thyrotropin pre- pared as a pituitary extract was essentially without teratogenic action. These observations raise the question of sample purity. Thyrotropin prepared from pituitary glands is tested for purity and the contaminants are known. The principal contaminants are other pituitary hormones at levels considered to be insignificant. The TSH derived from bovine serum, on the other hand, is only tested for its thyrotropic activity and no claims are made regarding possible impurities. Further study will be required to determine not only the impurities present

TABLE 3

Malformations observed following treatment of pregnant rats with 20 units thyrotropin

\begin{tabular}{|c|c|c|c|c|}
\hline \multirow[b]{2}{*}{ Malformation } & \multirow[b]{2}{*}{ Sigma } & \multirow[b]{2}{*}{ Armour } & \multicolumn{2}{|c|}{ NBC } \\
\hline & & & $\begin{array}{c}\text { No. } \\
6193\end{array}$ & $\begin{array}{c}\text { No. } \\
9753\end{array}$ \\
\hline Hydrocephalus & $1 / 7^{1}$ & - & $25 / 37$ & $7 / 26$ \\
\hline $\begin{array}{l}\text { Hydronephrosis } \\
\text { Hydroureter }\end{array}$ & $5 / 7$ & $5 / 5$ & $2 / 37$ & $8 / 26$ \\
\hline $\begin{array}{l}\text { Anopthalmia } \\
\text { Microphthalmia }\end{array}$ & - & - & $24 / 37$ & $19 / 26$ \\
\hline $\begin{array}{l}\text { Agnathia } \\
\text { Micrognathia }\end{array}$ & - & 一 & $4 / 37$ & $4 / 26$ \\
\hline Other & $1 / 7$ & - & $6 / 37$ & $13 / 26$ \\
\hline
\end{tabular}

1 No. showing defect/no. malformed animals.

TABLE 4

Effects of intraperitoneal injections of 20 units thyrotropin and a subteratogenic dose of trypan blue ${ }^{1}$

\begin{tabular}{|c|c|c|c|c|}
\hline $\begin{array}{l}\text { Source of } \\
\text { hormone }\end{array}$ & $\begin{array}{l}\text { No. } \\
\text { implantation } \\
\text { sites }\end{array}$ & $\begin{array}{l}\text { No. and \% } \\
\text { resorbed } \\
\text { or dead }\end{array}$ & $\begin{array}{l}\text { No. and \% } \\
\text { survivors } \\
\text { malformed }\end{array}$ & $\begin{array}{l}\text { \% implanta- } \\
\text { tion sites } \\
\text { affected by } \\
\text { treatment }\end{array}$ \\
\hline \multicolumn{5}{|l|}{ NIH } \\
\hline Alone & 59 & 0 & 0 & 0 \\
\hline With TB & 36 & 0 & 0 & 0 \\
\hline \multicolumn{5}{|l|}{ Armour } \\
\hline Alone & 111 & $9(8.1)$ & $5(4.9)$ & 12.6 \\
\hline With TB & 67 & $4(5.9)$ & $3(4.8)$ & 10.4 \\
\hline \multicolumn{5}{|l|}{ Sigma } \\
\hline Alone & 128 & $11(8.6)$ & $7(5.9)$ & 14.1 \\
\hline With TB & 115 & $15(13.1)$ & $5(5.0)$ & 17.7 \\
\hline \multicolumn{5}{|l|}{ NBC-s } \\
\hline No. 6193 alone & 224 & $74(33.0)$ & $37(24.6)$ & 49.6 \\
\hline No. 6193 with TB & 169 & $55(32.5)$ & $68(59.7)$ & 72.8 \\
\hline No. 9753 alone & 203 & $49(24.2)$ & $26(16.2)$ & 37.0 \\
\hline No. 9753 with TB & 96 & $26(27.2)$ & $70(35.6)$ & 52.2 \\
\hline Trypan blue alone & 122 & $1(0.8)$ & 0 & 0.8 \\
\hline
\end{tabular}

1 Thyrotropin injected gestation days $7,8,9$, and 10 ( $1 / 4$ dose each day). Trypan blue injected gestation day $8(0.6 \mathrm{mg} / 100 \mathrm{gm}$ maternal body weight $)$. 
in this thyrotropin but also the agent responsible for teratogenesis.

It is not known whether the different results obtained with Armour's thyrotropin are significant. This TSH was from the same lot but administered at two different times during the year. Treatment of rats in the spring resulted in malformations whereas treatment in the fall did not. At present no significance is attached to this observation, although it has been proposed that season of the year may affect human teratogenesis (Edwards, '51). Thyrotropin obtained from Sigma was from two different lots. All animals were treated between February and June of the same year. There was no difference in the incidence of malformations produced by the two samples, but a marked difference was noted in the incidence of resorption. The reason for this difference is not known.

It is difficult to postulate a teratogenic action for purified TSH. The facts obtained in this investigation do not warrant it nor do the observations of others. The fetus is apparently unaffected by TSH treatment of the mother in the guinea pig (Peterson and Young, '52) and rat (Tobin, '41). Hypophysectomy of pregnant rats has no effect on fetal thyroid histology (Hamburg, Sobel, Koblin, and Rinestone, '62) or fetal thyroid iodine uptake (Nikitovitch and Knobil, '55). These reports suggest the fetal thyroid to be free of maternal thyrotropin influence, presumably because thyrotropin does not cross the placenta from mother to fetus. A possible route of action could be through the thyroid gland. Thyroid dysfunction in pregnancy has been repeatedly investigated, but the exact role that the thyroid hormone plays in embryonic and fetal development is not known. The evidence is much stronger for reproductive failure and malformations during maternal hypothyroid states than during maternal hyperthyroidism (Mann, Shaver and Cooke, '58; Greenman, Gabrielson, Howard-Flanders and Wessel, '62). During the critical period of organogenesis there was clear histological evidence of stimulation of the maternal thyroid gland in all thyrotropin-treated animals in the present experiment.

The results obtained following treatment of pregnant rats with TSH in conjunction with a subteratogenic dose of trypan blue are in agreement with those following TSH treatment alone. There was no demonstrable interaction between TSH derived from pituitary glands and trypan blue. However, both TSH samples derived from serum interacted with the subteratogenic dose of trypan blue, causing a doubling in the incidence of malformations produced by TSH alone. The resorption rate was unaffected. Analysis of the types of malformations produced indicated that this interaction leads to an increase in the frequency of malformations of the type produced by the serumprepared TSH (Beaudoin and Roberts, '66), i.e., the teratogenic activity of serum TSH is augmented.

The answer to this problem of teratogenic action by serum-derived TSH must await further investigation into the method of preparation of the thyrotropin and the identification of the impurities presumed to be present.

\section{LITERATURE CITED}

Beaudoin, A. R., and J. M. Roberts 1966 Teratogenic action of the thyroid stimulating hormone and its interaction with trypan blue. J. Embryol. Exp. Morph., 15: 281-289.

Edwards, J. H. 1961 Seasonal incidence of congenital disease in Birmingham. Ann. Hum. Genet., 25: 89-93.

Greenman, G. W. M. O. Gabrielson, J. HowardFlanders and M. A. Wessel 1962 Thyroid dysfunction in pregnancy. New Eng. J. Med., 267: $426-431$.

Hamburgh, M., E. H. Sobel, R. Koblin and A. R. Rinestone 1962 Passage of thyroid hormone across the placenta in intact and hypophysectomized rats. Anat. Rec., 144: 219-227.

Mann, E. B., B. A. Shaver and R. E. Cooke 1958 Studies of children born to women with thyroid disease. Am. J. Obst. Gyn., 75: 728-741.

Nikitovitch, M., and E. Knobil 1955 Placental transfer of thyrotropic hormone in the rat. J. Clin. Endocr. Metab., 15: 837.

Peterson, R. R., and W. C. Young 1952 The problem of placental permeability for thyrotropin, propylthiouracil and thyroxine in the guinea pig. Endocrinology, 50: 218-225.

Tobin, C. 1941 Some effect of thyrotropic hormone on the pregnant rat. Proc. Soc. Exp. Biol. Med., 48: 592-595. 
PLATES 


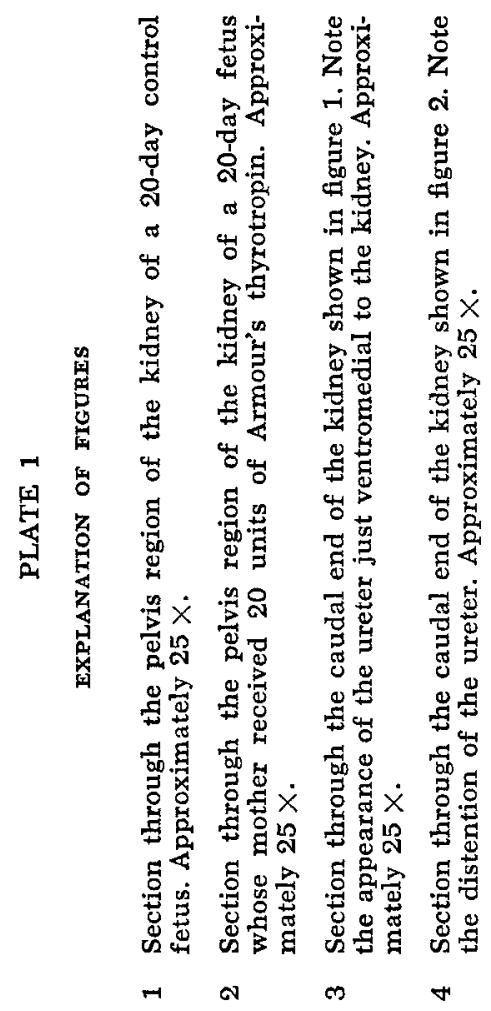



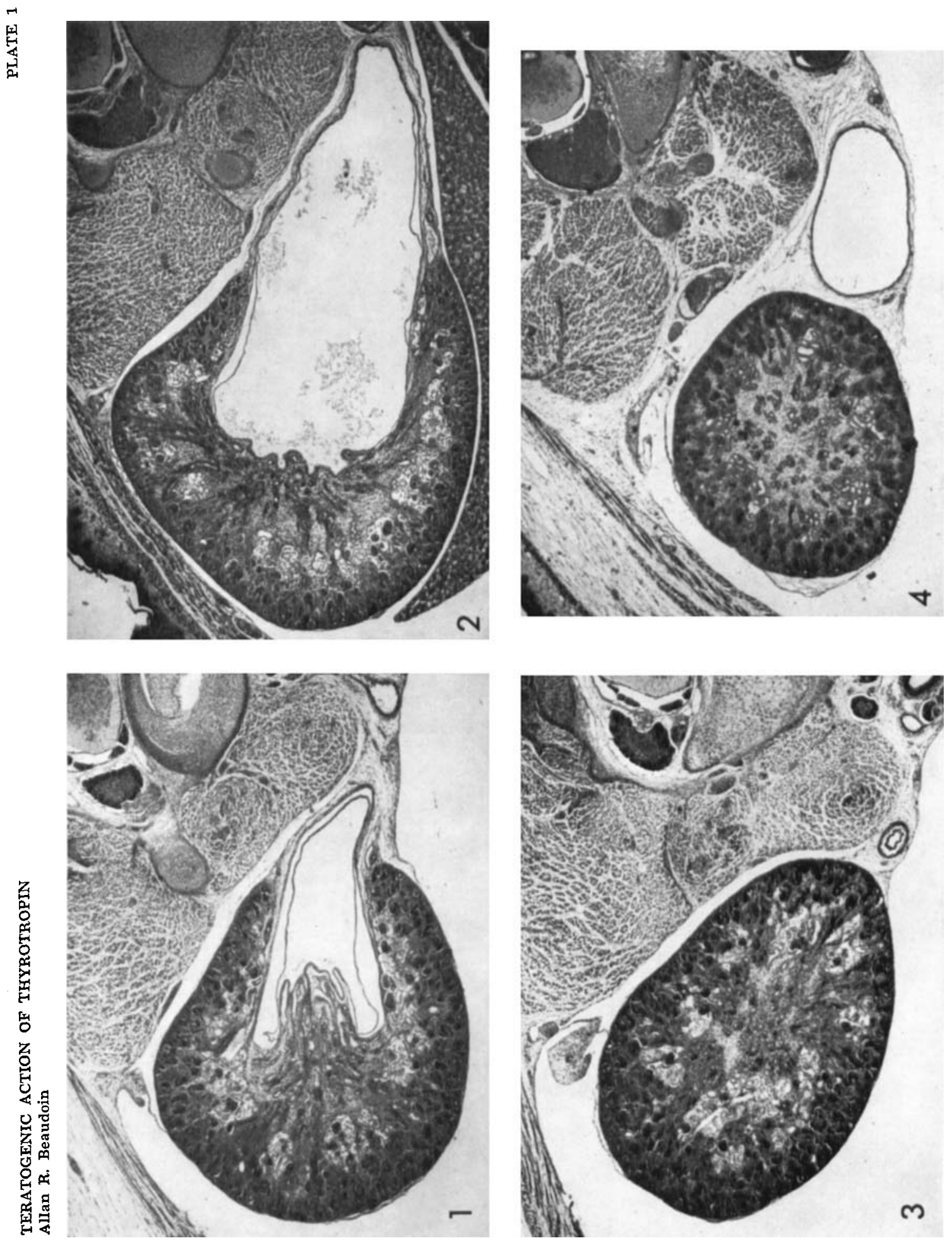
PLATE 2

EXPLANATION OF FIGURES

All fetuses illustrated are from mothers treated with 20 units of NBC serum-prepared thyrotropin.

5 Fetus showing agnathia and anophthalmia.

6 Fetus showing micrognathia and gastroschisis.

7 Fetus showing exencephaly and gastroschisis.

8 Fetus showing grossly abnormal head region. 

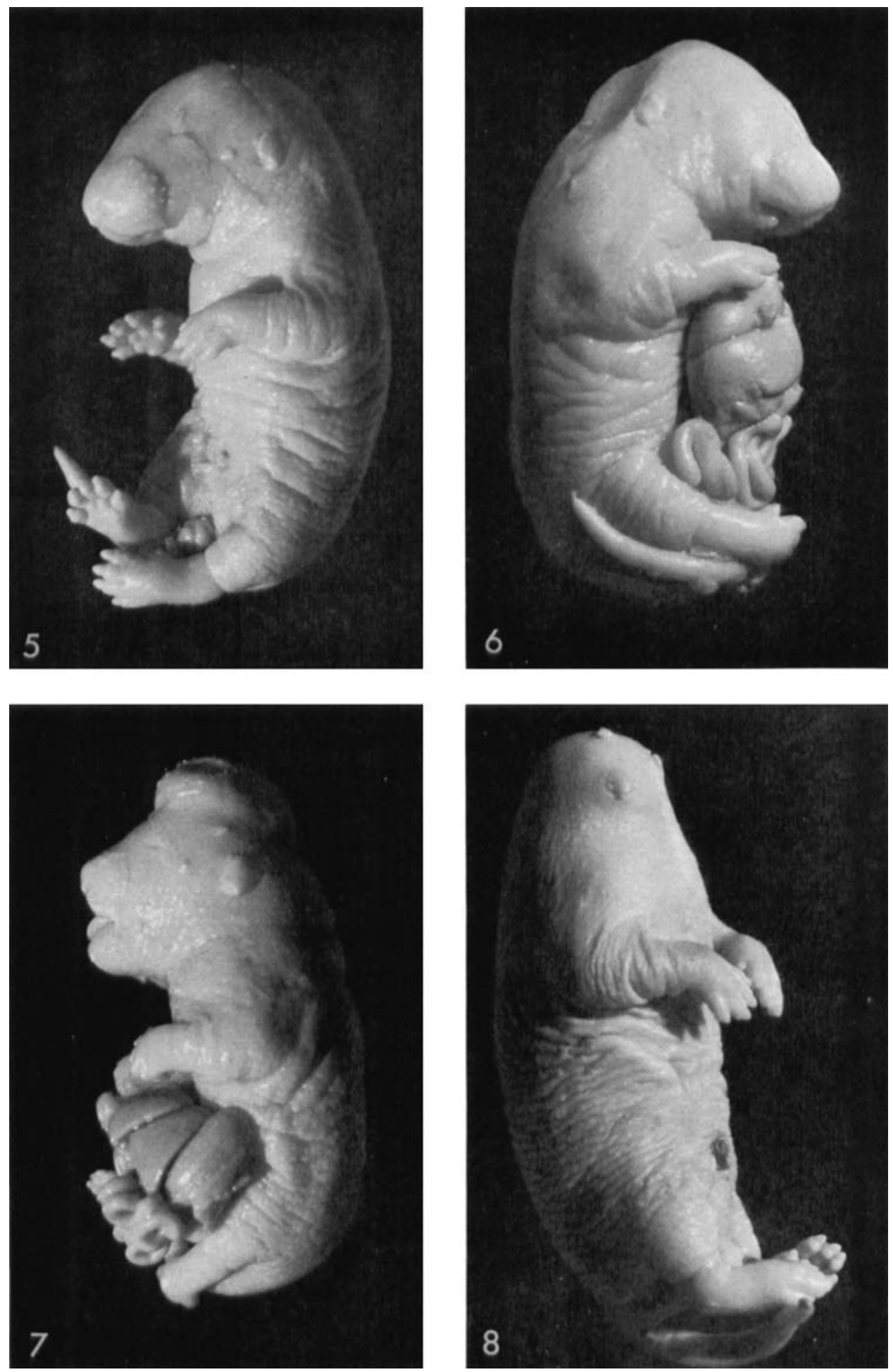